\title{
Effect of a Fragrant Tree on the Perception of Traffic Noise
}

\author{
Meihui BA ${ }^{\mathrm{a}}$, Jian KANG ${ }^{\mathrm{a}, \mathrm{b}^{*}}$
}

${ }^{a}$ Key Laboratory of Cold Region Urban and Rural Human Settlement Environment Science and Technology, Ministry of Industry and Information Technology, School of Architecture, Harbin Institute of Technology, Harbin, China. Bameihui@hotmail.com

${ }^{b}$ UCL Institute for Environmental Design and Engineering, University College London (UCL), London, United Kingdom. J.kang@ucl.ac.uk

*Corresponding Author: J.kang@ucl.ac.uk, UCL Institute for Environmental Design and Engineering, The Bartlett, University College London (UCL), London WC1H 0NN, United Kingdom. Tel: +44 (0)20 31087338

\footnotetext{
Abstract: This study investigated the effect of a fragrant tree on the perception of traffic noise, aiming to reveal the interaction between odour and sound in urban environment. Field research investigations including on-site measurement and questionnaire distribution were conducted in two conditions (with and without fragrance) in four streets in Harbin, China, where lilac had been planted. The results showed that fragrance could affect the perception of traffic noise, which was reflected in increased overall comfort of the street, decreased annoyance caused by traffic noise, and improvement in auditory and olfactory satisfaction. The subjective evaluation of a street where double rows of lilac were planted was superior to that of single-row streets, and a decrease in traffic noise annoyance was more evident when the streets had lower traffic noise levels. The study also found that the higher the congruency of the fragrance and the environment, the more comfortable and less annoyed people were. Finally, familiarity, preference, and subjective intensity of fragrance did not correlate with overall comfort or traffic noise annoyance.
}

Keywords: fragrance; traffic noise; multisensory perception 


\section{Introduction}

Among the many problems impacting the use of urban streets today, traffic noise is one of the most prevalent. The presence of traffic noise, particularly at higher intensity and volume, seriously threatens people's psychological and physiological health. Concomitantly, the improvement of people's living standards has led people to pay more attention to their psychological and emotional needs while raising their expectations for the acoustic environment of urban street space.

\subsection{Traffic noise}

The urban street is open public space, and with continuous urbanisation, the total mileage of urban areas has increased each year. At the beginning of the 1980s, the length of streets in China totalled only 30,000 kilometres; by the end of 2013, however, the total was more than 550,000 kilometres, and the ownership of civil vehicles had reached 126 million [1]. Thus, traffic noise has become the main source of noise pollution, which is one of the four major urban environmental contaminants.

Studies on the characteristics of traffic noise have found that urban structure, road conditions, vehicle type ratio, and traffic flow are the main factors that influence urban traffic noise levels [2-4]. Street traffic noise can cause physical and psychological harm to people such as impairment of hearing, cardiovascular system damage, and even mental illness [5-7]. In view of this, extensive research has been carried out on the control, management, and legislation of traffic noise. Noise control measures mainly concentrate on three aspects: noise source, noise transmission path, and receiver. In terms of implementation, Europe has several times lowered the allowable noise level of new cars $[8,9]$. Many countries have also carried out research on using environmental noise barriers [10]. In addition, some people have arranged their trips by car according to noise prediction maps $[11,12]$.

Noise annoyance is thus a generally applicable subjective evaluation indicator among the impacts of traffic noise [13]. In most cases, reducing sound pressure level will reduce people's annoyance [14]. However, studies have shown that lowering the sound level of traffic noise in urban open public spaces 
does not always reduce people's noise annoyance [15-17]. It can also be affected by many other factors, for instance, pavement type: the asphalt concrete has a lower annoyance rate than granite cubes [18]. Urban site typology can also affect traffic noise annoyance and sensitivity, which is higher in wide streets than in narrow streets [19]. Further, the masking action of sound can reduce the perception of noise. Galbrun and Ali found that water sounds can mask traffic noise and reduce traffic noise annoyance [20].

\subsection{Smell environment}

The urban olfactory environment is of great importance, but as the architect Herve Ellena points out, smell belongs to the 'dark side of architecture' and is often forgotten by designers [21]. Smell environment mainly depends on air quality, and odour, one characteristic of air quality, is often a source of complaints [22]. Odour can affect people's moods [23], including odours introduced into the environment [24], leading to further effects. Knasko found that introducing odour into a store can increase the amount of time that people remain [25]. Reinarz described the effect of odours on people in historical perspective [26]. Xiao et al. proposed a perceptual model of smellscape pleasantness, so that the olfactory environment could be systematically evaluated [27]. A city's smell can be divided into 3 levels: the background odour provides a macro-level base note; the dominant smell of specific regions blending with background odour forms the mid-level notes and always affects people, such as the smell of the sea, or of lawns; and micro-level smell refers to local smells that change drastically and frequently, for instance, the smell of people's perfume [28]. Mid-level smell often influences people's lives because of its dominance and variability; hence, it is the main focus of architecture and urban design. Mid-level odours in urban open public spaces are mainly emitted by plants (trees and flowers), food (markets, bakery, and restaurants), pollution (waste, traffic emission, and industrial odours), building materials and so on. Survey research shows that people favour plant fragrances most even if their preferences for odours vary widely [29]. D’Errico described the use of scents in new media and technology [30]. Further more, fragrance stimulates the part of the brain that controls emotion and changes cognitive performance [31]. 


\subsection{Multisensory perception}

Spence systematically summarized studies on multisensory integration in different fields [32]. The senses include vision, hearing, smell, taste, and touch. The first three have the opposite characteristics to the latter two in experiencing the outside world: vision, hearing, and smell often come from unconscious behaviour, and cannot be avoided at the beginning. Taste and touch are more dependent on people's subjective will; they do not tell us much about the surrounding environment [33]. The urban environment can only be partially grasped through taste and touch; therefore, vision together with hearing and smell are important mediums for perceiving a city.

Studies of audiovisual interaction have made some achievements, and results have shown that there is an interaction between vision and hearing. Southworth found that in the audiovisual environment, paying more attention to the visual landscape can lead to a decrease in hearing perception and vice versa [34]. Lercher and Schulte-Fortkamp found that people living in streets with beautiful scenery feel less annoyed by the acoustic environment, while those who lived in neighbourhoods with bad landscapes suffer more acoustic annoyance [35]. Hashimoto and Hatano discovered that good visual effects can reduce negative factors for sound quality evaluation, which might make people perceive a decrease in noise of more than $10 \mathrm{~dB}$ [36]. Another study found that enhancing or weakening a particular sound in a real place or in a picture display can strengthen visual perception in a situation where sound and vision are congruent [37]. D'Alessandro et al's study, which was carried out in a university's out-door area, found that sound types and visual changes affect sound perception in different seasons [38].

There are few studies, however, on the interaction of vision with the auditory and olfactory senses. Van Reekum et al. found that stimuli from odours and sounds alter visual evaluation [39]. Dinh et al. discovered that sounds and smells can enhance the memory of the tester through virtual reality technology, but the addition of visual details had no such effect [40]. There is even less research on the interaction between the auditory and olfactory senses. Michon and Chebat found that music and fragrance can affect shopping behaviour in shopping malls [41]. Ba and Kang investigated the interaction of sound and odour 
in urban environments through laboratory research, analysing interactive effects among sound type, volume, odour type and concentration; the results showed that sound and smell affect each other's perception [42].

\subsection{Research questions and hypotheses}

Previous studies have shown that the stimulation of certain senses can affect the cognition and feeling of other senses. This provides a theoretical basis for reducing the perception of traffic noise through the stimulation of olfactory factors. At present, most of the previous studies used laboratory simulation to control the stimuli of sensory variables, field research on the interaction between olfaction and audition is lacking. Even if the simulation variable control is accurate in the laboratory, it cannot replace the real feeling of the actual environment on site and in real time. As Engen commented, 'odour perception is situational, contextual, and ecological' [43].

Therefore, this paper aimed to study the influence of odour on subjects' evaluations of traffic noise of urban streets, and reduce the annoyance of traffic noise through the introduction of positive odour, so as to improve people's evaluation of the urban environment. The study used lilac fragrance as the olfactory control variable and investigated through field research methods. The following specific questions were put forward: (1) Does the fragrance affect the perception of traffic noise? (2) Does the congruency of the odour and the environment affect the perception of traffic noise? and finally, (3) Does people's olfactory experience of the fragrance affect the perception of traffic noise?

\section{Methods}

\subsection{Selection of fragrance source}

Lilac is a deciduous shrub or small tree that is widely planted in gardens and streets for ornamental purposes because of its elegant colours and fragrance, and is mainly distributed in south-eastern Europe 
and parts of Asia, with a growing history of thousands of years. China is the Asian distribution and diversity centre of lilac, which mainly grows in the south-west, north-west, north, and north-east of the country. Of about 13 types in total, the main species are Syringa oblata, Syringa oblata var. alba, and Syringa amurensis. Lilac is also one of the key trees in Chinese cities [44]. Therefore, the odour of lilac was chosen as the source of the city's fragrance.

\subsection{Selection of study location}

The following factors were considered when selecting streets as research subjects: the traffic noise was loud; fragrant trees were planted continuously on the streets at an even distance; people could smell the fragrance; there were no restaurants, coffee shops, markets, factories, or other places releasing odours; and, to avoid the interference of visual factors, the overall architectural style of the street was consistent. As a typical large Chinese city, Harbin has various scales of streets. It has many lilac of different species, and each tree was planted 1.5 to $2 \mathrm{~m}$ apart. Lilac has been cultivated for more than 100 years in Harbin, and it was designated the city flower in 1988. Accordingly, this study selected Qingbin Road, Cehui Road, Xuefu Sandao Street, and Minsheng Road as the research subjects (hereinafter referred to as Street 1, Street 2, Street 3, and Street 4, respectively). The streets' widths are between 15 and 20 meters, which are typical urban street scales in China [45]. The specific parameters of each street are shown in Table 1.

Table 1. Parameters of the research subjects

\begin{tabular}{|c|c|c|c|c|c|c|c|}
\hline Location & Width & $\begin{array}{l}\text { Distance } \\
\text { of the } \\
\text { trees } \\
\text { from } \\
\text { road }\end{array}$ & $\begin{array}{l}\text { Lilac } \\
\text { species }\end{array}$ & Lilac planting modes & On-site photos & $\begin{array}{l}\text { Sample } \\
\text { number } \\
\text { (without } \\
\text { fragrance) }\end{array}$ & $\begin{array}{l}\text { Sample } \\
\text { number } \\
\text { (with } \\
\text { fragrance) }\end{array}$ \\
\hline Street 1 & $20 \mathrm{~m}$ & $5 \mathrm{~m} / 0.5 \mathrm{~m}$ & $\begin{array}{c}\text { Syringa } \\
\text { oblata }\end{array}$ & & & 55 & 53 \\
\hline Street 2 & $20 \mathrm{~m}$ & $5 \mathrm{~m}$ & $\begin{array}{c}\text { Syringa } \\
\text { oblata }\end{array}$ & & & 52 & 53 \\
\hline
\end{tabular}




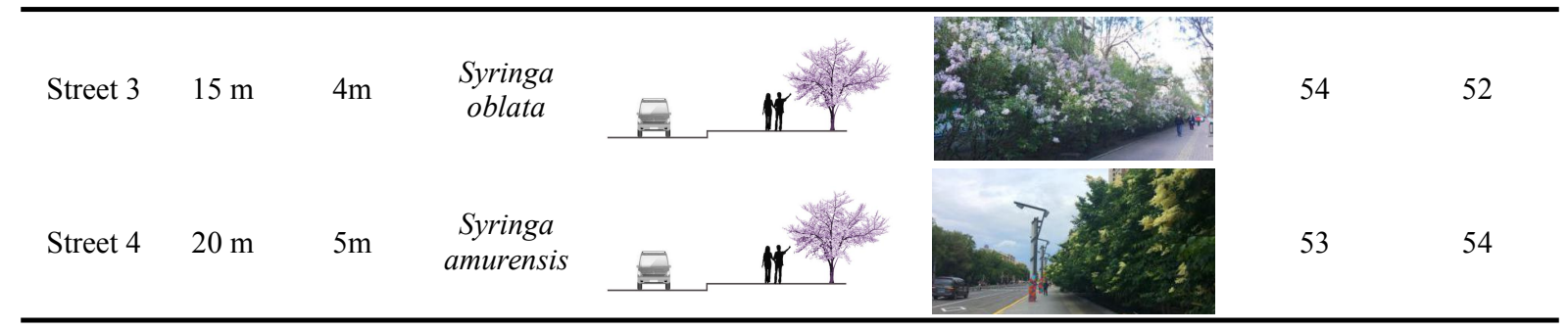

\subsection{Questionnaire design}

The questionnaire covered three aspects of perception: environment, traffic noise, and odour. The aim of this study was to reveal the multisensory perception of smell and hearing, but when people were asked about the feeling of one sense, they unintendedly felt only the specified sense and ignored the interactive experience of the senses. Therefore, participants were asked about the overall comfort of the street at first to avoid asking about a single sense, which could lead to a preconceived impression. To avoid the interference of visual factors, the question of satisfaction about the street's visual environment was also set up. The intention was to analyse whether there was a visual difference between the street with and without fragrance.

Knasko has proposed a concept of odour 'congruency', that is, how well the odour matches or how congruent it is with some aspect of the environment [25]. Even though certain odours are normally perceived to be pleasant, when they are incongruent with the surrounding environment, they can still make people who smell them feel uncomfortable. Moreover, foul odours and noise may not produce antipathy when they are in harmony with the environment [29]. Just as the sound environment contains a multitude of different sounds, the olfactory environment also contains various smells, especially for streets which are not absolutely odourless because they also contain macro background odours such as the smell of slight pollutants from the air itself. So in order to investigate the difference of congruency between odour and environment both with and without fragrance, subjects were asked the question of congruency both circumstances.

Olfactory experience in life and work—-such as familiarity, preference for odours, or subjective 
intensity — can also affect the perception of the environment [46]. Thus, in the study, the indicators of people's olfactory experience included the former three. Here, 'familiarity' reflects how familiar the respondents were with the fragrance, while 'preference' refers to the preference for the flower odour itself, and 'subjective intensity' means subjective evaluation of (objective) concentration.

For the perception of smell, when people are directly asked whether they can smell an odour, they sometimes may give an affirmative answer even if they do not smell it. In this study, the participants were instructed to list the odours they smelled; this was also done to avoid the impact of other interferential smells. No respondents listed other odours in the questionnaires. Similarly, the subjects were asked to list the sounds they heard; the results showed that no other sound sources were mentioned. The main goal of pedestrians is to walk through an area; they hardly speak during passage. In this case, traffic noise was relatively high, almost all of the experimental streets were next to residence, and there were no street shops, restaurants, or similar which could bring other sounds. Therefore, no other interference noise was perceived. Participants' replies were evaluated on a 5-point Likert-type scale as follows: very unsatisfied, unsatisfied, moderate, satisfied, and very satisfied (1 (lowest) to 5 (highest)).

Participants were asked to rate the following three aspects:

\section{Environment perception:}

-Overall comfort (very uncomfortable to very comfortable)

-Visual satisfaction (very unsatisfied to very satisfied)

-Auditory satisfaction (very unsatisfied to very satisfied)

-Olfactory satisfaction (very unsatisfied to very satisfied)

\section{Noise perception:}

-Traffic noise annoyance (not very annoying to very annoying)

\section{Fragrance perception:}

-Congruency between odour and environment (very incongruent to very congruent) 
-Fragrance familiarity (very unfamiliar to very familiar)

-Fragrance preference (disliked very much to very much liked)

-Fragrance subjective intensity (very light to very strong)

\subsection{Questionnaire distribution scope}

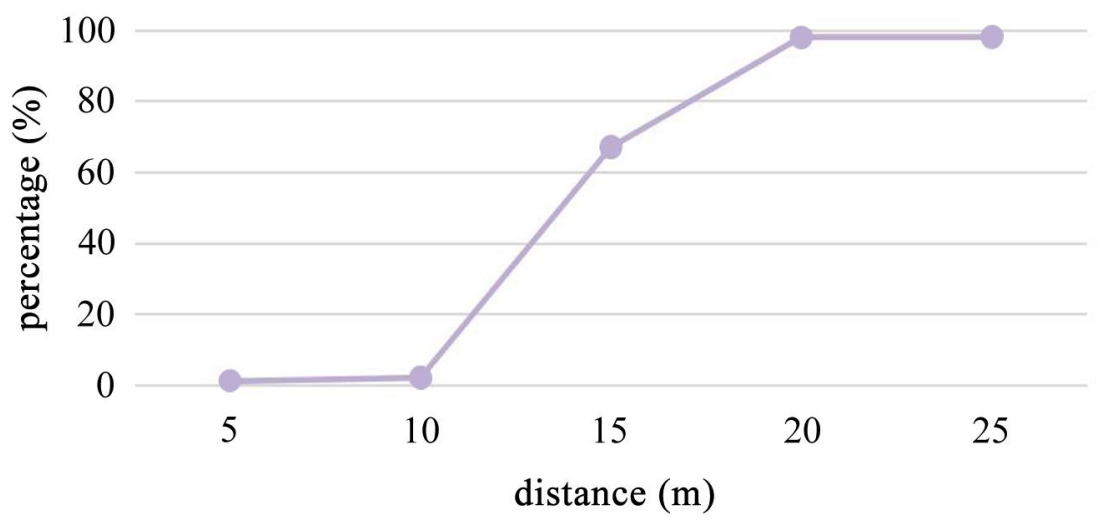

Fig. 1. The distance from the street end and the percentage of participants who smelled the fragrance

The study found that in the same street, because of the layout of the buildings and the location of the intersection, people at the marginal area of the street were unable to perceive the fragrance due to a low odour concentration caused by edge effect and wind action. Therefore, the questionnaires were randomly distributed in the marginal and middle areas of the street that corresponded to the research areas without and with fragrance. Pre-research on the research scope was carried out at first; the study distributed at least 30 questionnaires in each range of 5 meters, and a total of 156 questionnaires were collected. This showed that the proportion of people who could smell the fragrance within 10 meters from the end of the street was $2 \%$, and about $98 \%$ of participants could smell the fragrance in streets over $20 \mathrm{~m}$ from the end, as shown in Figure 1. Therefore, $200 \mathrm{~m}$ in the street was selected as the research range; as shown in Figure 2, the marginal area was located within 10 meters from the end as the research range without fragrance, and the middle area was situated over 20 meters away from the end as the research range with fragrance. In order to avoid differences in the basic physical environment caused by time factors, the questionnaires were distributed at the same time both in the marginal and middle areas of the streets, from 
9:00 am to 17:00 $\mathrm{pm}[47,48]$. The questionnaire sampling interval time was 5 minutes, and the duration was controlled within 5 minutes. A total of 426 valid questionnaires were collected $(53.9 \%$ female, average age 48), and their reliability and validity were tested before the statistical analysis in order to verify the results [49]. The number of samples is shown in Table 1.

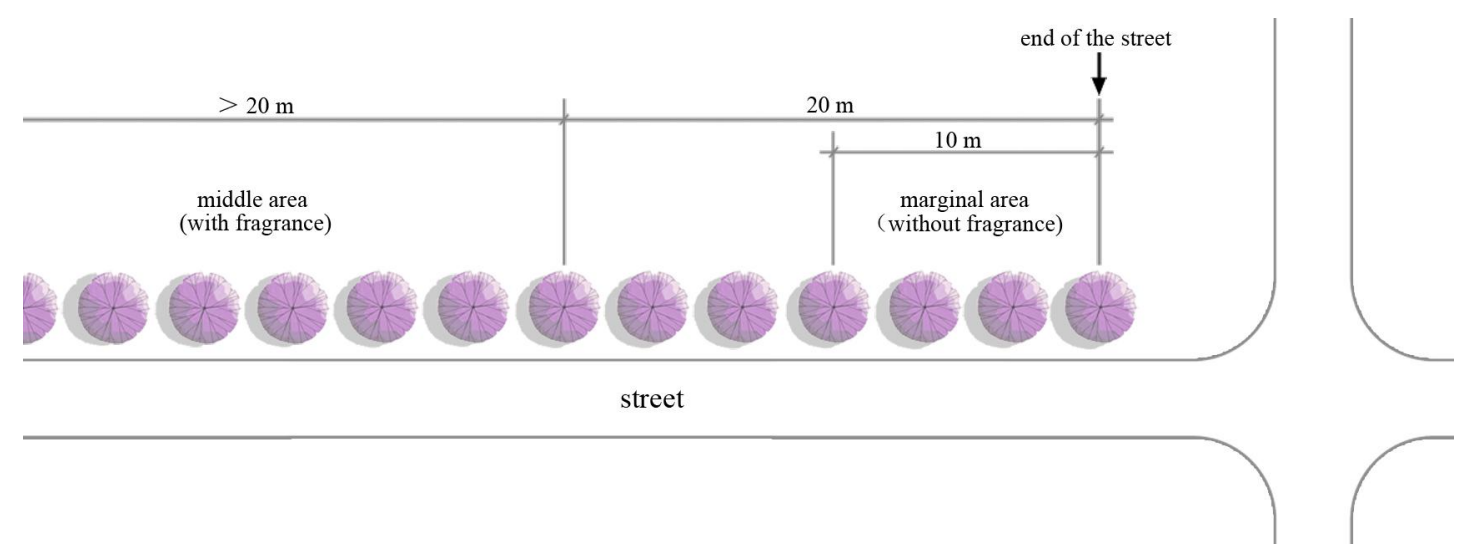

Fig. 2. Research scope layout : middle area is for the condition with fragrance; marginal area is for the condition without fragrance

\subsection{Objective measurement}

The measurement of odour concentration as an air quality feature is very complicated. In this study, odour concentration was measured by the participants' subjective evaluation, because the urban smellscape is not integrated and clear compared to the visual, auditory, and tactile environments, which might make more objective measurement difficult. Thus, detection at any single time or place cannot represent the olfactory environment of the entire region [50]. The experiment was carried out in May, when the lilacs were in full bloom, and the microclimate was monitored. The test was set up when the fragrant trees were upwind to the sidewalk and the temperature and humidity were stable. To avoid the influence of physical factors on the experiment, it was performed when the wind speed was below $4 \mathrm{~m} / \mathrm{s}$, the temperature was $26{ }^{\circ} \mathrm{C}$ to $28^{\circ} \mathrm{C}$, the humidity was $30 \%$ to $35 \%$, and the air quality index was under 50 [49]. After the participant finished the questionnaire, the sound pressure level was measured immediately every 10 seconds, and a continuous measurement was taken for 1 minute. This is because 
during the questionnaire survey, the subjects often asked questions, so that the background sound level was affected. The sound meter was $1.5 \mathrm{~m}$ on the ground and at least $1.2 \mathrm{~m}$ from any possible reflector to avoid the interference of reflected sound [51]. The objective measurement parameters of streets during the experiment are shown in Table 2; there were no significant differences in the indicators between the same street with and without fragrance $(p>.05)$. Therefore, these factors can be excluded as causes of different evaluation results in the presence or absence of odour.

Table 2. Objective measurement parameters of streets

\begin{tabular}{cccccccccc}
\hline \multirow{2}{*}{ Location } & $\begin{array}{c}\text { Fragrance } \\
\text { condition }\end{array}$ & $\begin{array}{c}\text { A-weighted } \\
\text { sound } \\
\text { pressure } \\
\text { level }\end{array}$ & $\begin{array}{c}\text { Average } \\
\text { traffic } \\
\text { speed } \\
(\mathrm{km} / \mathrm{h})\end{array}$ & $\begin{array}{c}\text { Average } \\
\text { vehicle } \\
\text { flow } \\
(\mathrm{per} \\
\text { hour })\end{array}$ & $\begin{array}{c}\text { wind } \\
\text { speed } \\
(\mathrm{m} / \mathrm{s})\end{array}$ & $\begin{array}{c}\text { Dominant wind } \\
\text { direction }\end{array}$ & $\begin{array}{c}\text { Average } \\
\text { temperature } \\
\left({ }^{\circ} \mathrm{C}\right)\end{array}$ & $\begin{array}{c}\text { Average } \\
\text { humidity } \\
(\%)\end{array}$ & $\begin{array}{c}\text { Air } \\
\text { quality } \\
\text { index }\end{array}$ \\
\hline \multirow{2}{*}{ Street1 } & Present & 66.7 & 43.3 & 1035 & 2.1 & $4.9^{\circ}$ south-east & 27.2 & 32.2 & 37 \\
& Absent & 66.2 & 42.0 & 1029 & 1.8 & $4.5^{\circ}$ south-east & 27.3 & 31.8 & 37 \\
\hline \multirow{2}{*}{ Street2 } & Present & 67.3 & 45.0 & 1020 & 1.8 & $5.1^{\circ}$ south-east & 26.8 & 33.1 & 33 \\
& Absent & 67.3 & 46.1 & 1026 & 2.0 & $5.3^{\circ}$ south-east & 26.8 & 32.5 & 33 \\
\hline \multirow{2}{*}{ Street3 } & Present & 71.2 & 42.7 & 1148 & 2.3 & $5.6^{\circ}$ south-west & 27.1 & 32.4 & 37 \\
& Absent & 71.0 & 42.0 & 1138 & 2.4 & $5.3^{\circ}$ south-west & 26.8 & 32.8 & 37 \\
\hline \multirow{2}{*}{ Street4 } & Present & 69.8 & 45.6 & 722 & 2.2 & $6.1^{\circ}$ south-west & 26.9 & 33.5 & 41 \\
& Absent & 70.1 & 46.4 & 730 & 1.9 & $6.9^{\circ}$ south-west & 27.0 & 32.9 & 41 \\
\hline
\end{tabular}

\subsection{Data analysis}

SPSS 21.0 was used to establish a database containing all the subjective and objective results [52]. The data were analysed using the following methods: a mean differences $t$-test (2-tailed) for the objective measurement indicators and subjective evaluation indicators for streets with and without fragrance, and a partial correlation analysis to calculate the relationships between subjective evaluation indicators, to avoid the influence of visual factors.

\section{Results and analysis}

\subsection{The effect of fragrance}

A separate-samples $t$-test was performed on the subjective evaluation of the people on the four 
streets, as shown in Table 3. The results showed there were significant differences in overall comfort

(except in Street 3), traffic noise annoyance, auditory satisfaction, and olfactory satisfaction on the streets with and without fragrance, but no significant difference in visual satisfaction. This indicated that fragrance could affect the people's perception of the environment and traffic noise. Visual satisfaction showed no difference for the perception of the visual environment from the end and middle of the streets; hence, the effect of visual factors was excluded.

Table 3. Mean ratings and standard deviation of the indicators between location and fragrance condition

\begin{tabular}{|c|c|c|c|c|c|c|c|c|c|c|c|}
\hline Location & $\begin{array}{l}\text { Fragrance } \\
\text { condition }\end{array}$ & Statistics & $\begin{array}{l}\text { Overall } \\
\text { comfort }\end{array}$ & $\begin{array}{c}\text { Traffic } \\
\text { noise } \\
\text { annoyance }\end{array}$ & $\begin{array}{c}\text { Visual } \\
\text { satisfaction }\end{array}$ & $\begin{array}{c}\text { Auditory } \\
\text { satisfaction }\end{array}$ & $\begin{array}{c}\text { Olfactory } \\
\text { satisfaction }\end{array}$ & Congruency & Familiarity & Preference & $\begin{array}{c}\text { Subjective } \\
\text { intensity }\end{array}$ \\
\hline \multirow{5}{*}{ Street 1} & \multirow{2}{*}{ Absent } & Mean & 3.49 & 3.49 & 3.85 & 2.60 & 3.05 & 3.11 & - & - & - \\
\hline & & SD & .540 & .573 & .405 & .655 & .488 & 0.69 & - & - & - \\
\hline & \multirow{3}{*}{ Present } & Mean & 3.89 & 3.15 & 3.85 & 3.15 & 3.94 & 3.81 & 4.34 & 4.09 & 3.57 \\
\hline & & SD & .423 & .601 & .456 & .632 & .534 & 0.62 & 0.517 & 0.658 & 0.605 \\
\hline & & Sig. & 0.000 & 0.003 & 0.947 & 0.000 & 0.000 & 0.000 & - & - & - \\
\hline \multirow{5}{*}{ Street 2} & \multirow{2}{*}{ Absent } & Mean & 3.42 & 3.62 & 3.81 & 2.58 & 3.08 & 3.06 & - & - & - \\
\hline & & SD & .605 & .565 & .487 & .637 & .555 & 0.73 & - & - & - \\
\hline & \multirow{3}{*}{ Present } & Mean & 3.72 & 3.34 & 3.87 & 3.09 & 3.92 & 3.53 & 4.19 & 4.06 & 3.40 \\
\hline & & SD & .601 & .649 & .556 & .766 & .646 & 0.80 & 0.557 & 0.456 & 0.531 \\
\hline & & Sig. & 0.014 & 0.022 & 0.556 & 0.000 & 0.000 & 0.002 & - & - & - \\
\hline \multirow{5}{*}{ Street 3} & \multirow{2}{*}{ Absent } & Mean & 3.22 & 3.63 & 3.43 & 2.52 & 3.04 & 2.98 & - & - & - \\
\hline & & $\mathrm{SD}$ & .604 & .560 & .602 & .574 & .513 & 0.658 & - & - & - \\
\hline & \multirow{3}{*}{ Present } & Mean & 3.40 & 3.37 & 3.35 & 2.96 & 3.81 & 3.42 & 4.31 & 4.02 & 3.38 \\
\hline & & $\mathrm{SD}$ & .634 & .525 & .556 & .559 & .658 & 0.871 & 0.544 & 0.542 & 0.565 \\
\hline & & Sig. & 0.134 & 0.014 & 0.481 & 0.000 & 0.000 & 0.012 & - & - & - \\
\hline \multirow{5}{*}{ Street 4} & \multirow{2}{*}{ Absent } & Mean & 3.43 & 3.57 & 3.81 & 2.53 & 3.06 & 3.04 & - & - & - \\
\hline & & SD & .537 & .537 & .441 & .668 & .497 & 0.678 & - & - & - \\
\hline & \multirow{3}{*}{ Present } & Mean & 3.78 & 3.28 & 3.85 & 3.07 & 3.87 & 3.63 & 4.26 & 4.06 & 3.57 \\
\hline & & SD & .502 & .452 & .452 & .610 & .646 & 0.708 & 0.521 & 0.627 & 0.602 \\
\hline & & Sig. & 0.001 & 0.003 & 0.640 & 0.000 & 0.000 & 0.000 & - & - & - \\
\hline
\end{tabular}

Sig. = significance; $\mathrm{SD}=$ standard deviation; significance at 0.05 is in bold.

The main control variable in the street was the fragrance, and there was significant difference in the subjective evaluation indicators (Figure 3). The overall comfort, auditory satisfaction, and olfactory satisfaction on the four streets without fragrance were lower than that of the streets with fragrance, and the traffic noise annoyance was exactly the opposite. This means that the presence of fragrance could increase people's evaluation of the urban street environment and could reduce the perception of traffic noise. The mean value of the overall comfort level increased by 0.40 , the traffic noise annoyance decreased by 0.34 , the auditory satisfaction increased by 0.55 , and the olfactory satisfaction increased by as high as 0.89 (on a 5-point scale). Some of the participants in the test said 'the fragrance makes me feel 
better, and the traffic noise is not as annoying as the street without it'. Others said 'I'm focusing on my nose when I smell the flowers, but ignoring the noise of the traffic, sometimes I cannot even hear it'.

The mean difference in terms of overall comfort, traffic noise annoyance, auditory satisfaction, and olfactory satisfaction between the streets with and without fragrance was the largest in Street 1 . The overall comfort of Street 1 was the most among the 4 streets: the traffic noise annoyance was the lowest and the auditory satisfaction and olfactory satisfaction were the highest. The lilacs on Streets 2, 3, and 4 were all grown in single rows. The overall comfort of Street 4 was the highest among them, while its traffic noise annoyance was the lowest. The mean differences in the four evaluation indicators were lowest for Street 3, and its overall comfort was also the lowest among the four streets and the traffic noise annoyance the highest.
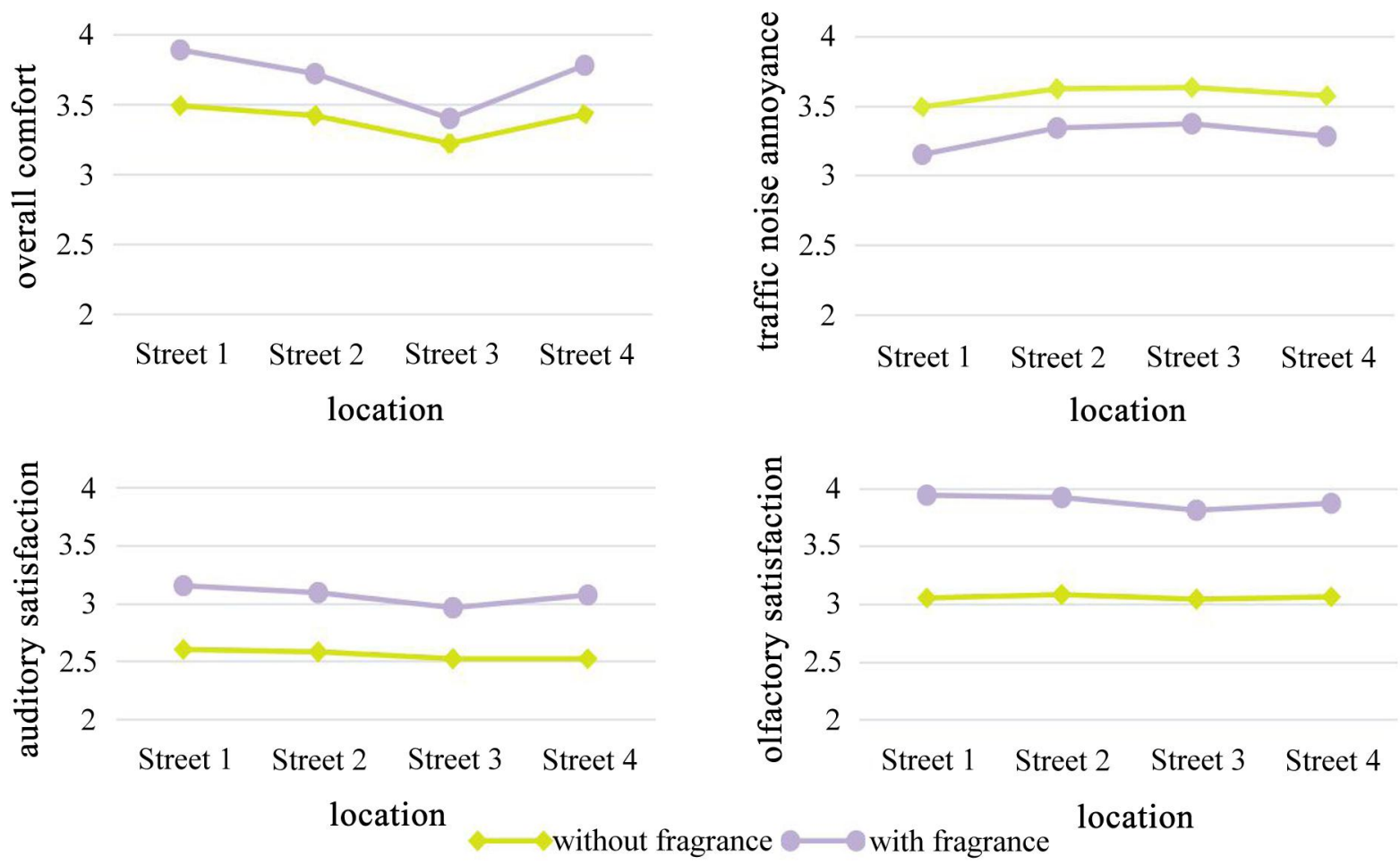

Fig. 3. Mean ratings for evaluation indicators between location and fragrance condition

Street 1 had the largest mean difference among all evaluation indicators, both with and without fragrance. This might be because the lilac trees on Street 1 were planted in double rows; thus, the fragrance was more aromatic than on the single-row streets, and people were therefore more satisfied and 
comfortable. Because the focus on smell was stronger than on hearing, the annoyance of traffic noise also decreased most in Street 1. Among the single-row streets, Street 4 had the highest evaluation; this might be because the trees on Street 4 were Syringa amurensis, which is a small tree of about $5 \mathrm{~m}$ with large inflorescence and long flowering phase, whose fragrance is stronger than that of Syringa oblata [53]; therefore, sound perception would have been affected much more. Traffic noise annoyance of Street 3 was the highest; this might owe to the presence of a bus stop in the lilac area and to the fact that its large-scale vehicle ratio was the greatest; thus, the sound pressure level, with a maximum difference of 5 decibels, was the highest among all the streets. The buses also produced greater additional noise in the process of deceleration and acceleration [54]; consequently, the effect of the fragrance was not as evident as on the other streets.

\subsection{The effect of congruency between odour and environment}

The results show there was a significant difference in the congruency of the odour and the environment $(p=.000<.05)$ between the streets with and without fragrance. Congruency was much higher on streets with fragrance $(M=3.59, S D=0.78)$ than on those without it $(M=3.07, S D=0.69)$. The specific results for each street are shown in Table 3. Street 1 had the highest congruency; Streets 2 and 4 were next, while Street 3 was lowest; in no case did any participant think that the fragrance was 'very incongruent' with the environment.

Figure 4 shows the proportion of participants with different opinions on the congruency of the four streets. As shown in Figure 4a, more than $60 \%$ of participants on Street 1 thought the congruency was moderate when the street lacked fragrance, and more than $80 \%$ thought fragrance and environment were congruent when the street was fragrant. The proportion of participants who chose 'not congruent' when the street was fragrant was about one-half that of those without fragrance. The proportion of participants who thought fragrance and environment were congruent was largest in Street 1; this might be because the lilac trees on Street 1 were planted in double rows, which led to a high concentration of fragrance, and so 
the influence on congruency was also greater than on other streets. Streets 2, 3, and 4 had similar trends as shown in Figures $4 \mathrm{~b}$ and $4 \mathrm{c}$. Streets 2 and 3 had a proportion of about $60 \%$ of participants who thought the congruency was moderate when the street lacked fragrance. The proportion of participants who thought the odour and environment were congruent was also $60 \%$ with fragrance, while the 'incongruent' selection attained about $20 \%$ both with and without fragrance. Figure $4 \mathrm{~d}$ shows the proportion of participants who thought odour and environment were congruent when there was fragrance was about $10 \%$ larger than those participants who thought it was moderate without fragrance. There was still a trend where the proportion of participants who chose 'not congruent' on the street with fragrance was about one-half that without fragrance. Some participants who believed that the odour and environment were congruent said the lilac fragrance was very well integrated with the environment, while those who thought they were not congruent explained that 'the fragrance of the lilac makes a great addition to the environment, but the traffic noise here is out of place; the strong contrast between good and bad is so incongruent'. It can be seen that there was polarisation between congruency and incongruency, but a majority of participants thought there was congruency between fragrance and environment. 


$$
100
$$

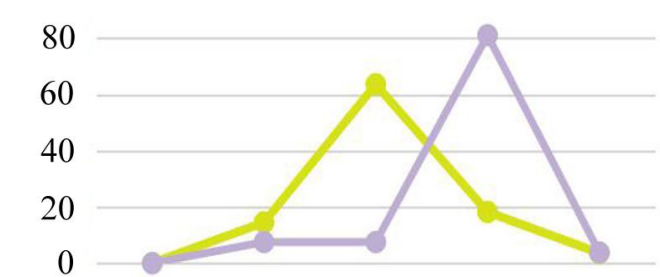

a
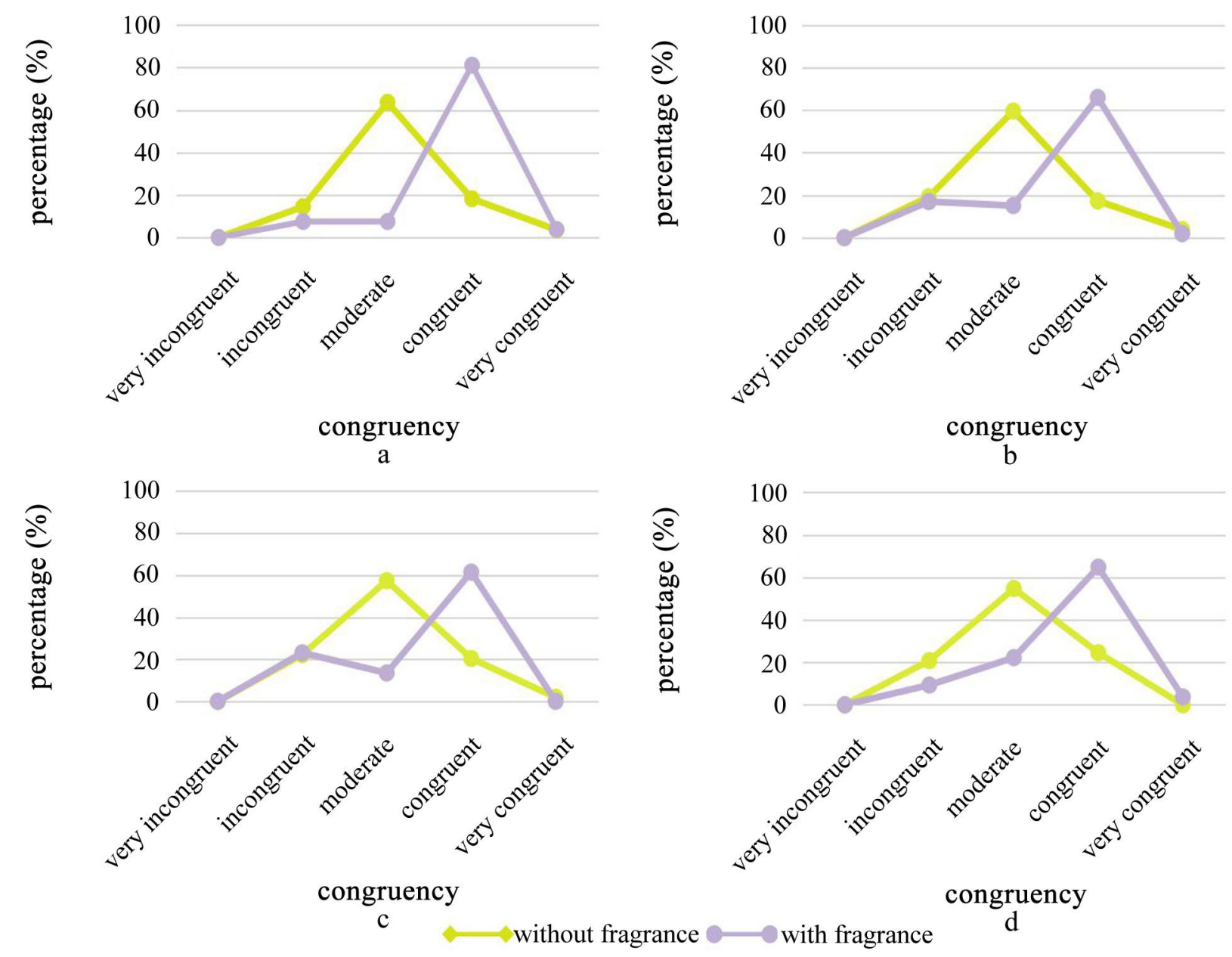

Fig. 4. Percentage of participants with different opinions on the congruency with and without fragrance: a. Street 1; b. Street 2; c. Street 3; d. Street 4.

To eliminate the influence of visual factors, a partial correlation analysis was performed for congruency, overall comfort and traffic noise annoyance, as shown in Table 4 . When the streets were fragrant, significant moderately positive correlations existed between the congruency and overall comfort, while the congruency was significantly and negatively correlated to traffic noise annoyance, and the absolute values of all the correlation coefficients were more than 0.4 . When the fragrance was absent, there was still a significant moderately positive correlation between the congruency and the overall comfort, while the congruency and traffic noise annoyance also showed a significantly low negative correlation; the absolute values were also more than 0.4 . This demonstrates that lilac can improve congruency between odour and environment. It also demonstrates that the more congruent the fragrance and environment, the more comfortable the people felt; moreover, there was lower traffic noise 
annoyance in such cases.

Table 4. Partial correlation coefficients between evaluation indicators and overall comfort and traffic noise annoyance

\begin{tabular}{|c|c|c|c|c|c|c|}
\hline Location & Variable & Fragrance condition & Congruency & Familiarity & Preference & $\begin{array}{c}\text { Subjective } \\
\text { intensity }\end{array}$ \\
\hline \multirow{4}{*}{ Street 1} & \multirow{2}{*}{ Overall comfort } & Present & $.568^{* *}$ & .155 & .184 & .176 \\
\hline & & Absent & $.523^{* *}$ & - & - & - \\
\hline & \multirow{2}{*}{$\begin{array}{l}\text { Traffic noise } \\
\text { annoyance }\end{array}$} & Present & $-.440^{* *}$ & .005 & -.045 & -.253 \\
\hline & & Absent & $-.447^{* *}$ & - & - & - \\
\hline \multirow{4}{*}{ Street 2} & \multirow{2}{*}{ Overall comfort } & Present & $.413^{* *}$ & .010 & .109 & .137 \\
\hline & & Absent & $.479^{* *}$ & - & - & - \\
\hline & \multirow{2}{*}{$\begin{array}{l}\text { Traffic noise } \\
\text { annoyance }\end{array}$} & Present & $-.433^{* *}$ & -.090 & -.143 & -.105 \\
\hline & & Absent & $-.455^{* *}$ & - & - & - \\
\hline \multirow{4}{*}{ Street 3} & \multirow{2}{*}{ Overall comfort } & Present & $.432^{* *}$ & .062 & .177 & .077 \\
\hline & & Absent & $.496^{* *}$ & - & - & - \\
\hline & \multirow{2}{*}{$\begin{array}{l}\text { Traffic noise } \\
\text { annoyance }\end{array}$} & Present & $-.429^{*}$ & -.156 & -.210 & .188 \\
\hline & & Absent & $-.410^{* *}$ & - & - & - \\
\hline \multirow{4}{*}{ Street 4} & \multirow{2}{*}{ Overall comfort } & Present & $.624^{* *}$ & .145 & .104 & .011 \\
\hline & & Absent & $.541^{* *}$ & - & - & - \\
\hline & \multirow{2}{*}{$\begin{array}{l}\text { Traffic noise } \\
\text { annoyance }\end{array}$} & Present & $-.459^{* *}$ & -.125 & -.089 & -.188 \\
\hline & & Absent & $-.455^{* *}$ & - & - & - \\
\hline
\end{tabular}

$* *$ Significance at 0.05 .

\subsection{The effect of people's olfactory experience of fragrance}

The results of the indicators of people's olfactory experiences showed that Streets 1 and 3 were highest in fragrance familiarity, as shown in Table 3. Street 4 was second, and Street 2 was the lowest. All mean values were greater than 4 (on a 5-point scale), which probably owed both because lilac is a common greening tree species in the city, and people are familiar with the smell. Preferences were very much the same in the results. The mean values of the four streets were also greater than 4 (on a 5-point scale), indicating that participants strongly accepted the smell of lilac. With regard to the subjective intensity of fragrance, Streets 1 and 4 were higher than Streets 3 and 2 by 0.2 . The reason was that Street 1's lilacs were planted in double rows, and Street 4 was different from the other three because of the species of lilac planted; its distinctive characteristics resulted in a more intense smell than the other species.

The specific percentages of participants with different opinions about the indicators of people's olfactory experience are shown in Figure 5. The overall tendency of the choice proportion of the 
fragrance's familiarity, preference, and subjective intensity in the 4 streets was unified. Most of the participants chose 'familiar' or 'very familiar'; no one chose 'unfamiliar' or 'very unfamiliar' with the fragrance. Almost $65 \%$ of participants considered each street 'familiar' and 'very familiar' was the least on Street 2. This may be because most participants were native to the city, but there were more universities near Street 2; thus, more students tested on Street 2 than on the other three streets, and non-locals among the students might not be familiar with the smell of lilac.
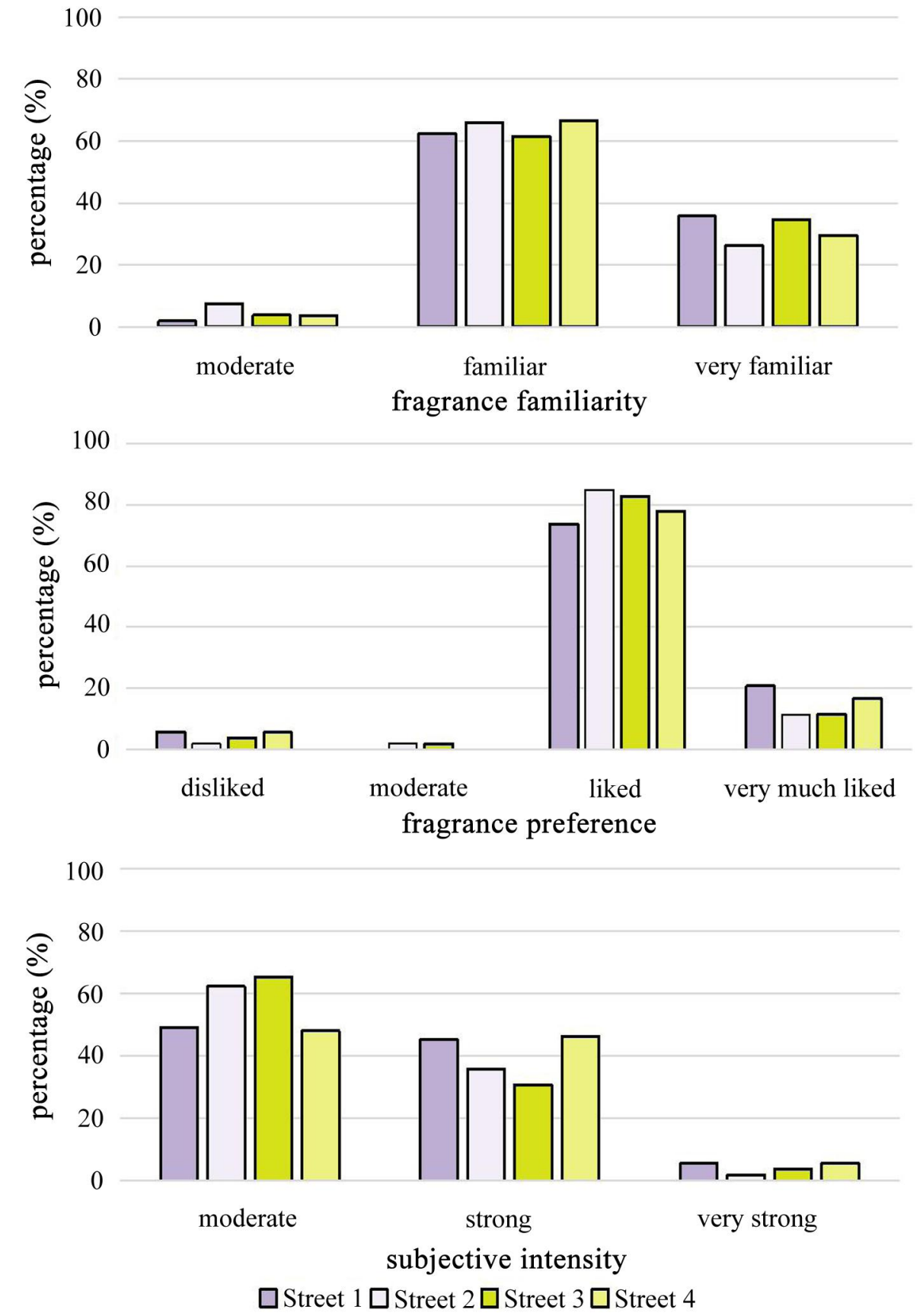
Fig. 5. Percentage of participants with different opinions on the indicators of people's olfactory In terms of fragrance preference, nearly $80 \%$ of the participants liked it, about $15 \%$ liked it very much, and none disliked it very much; very few disliked it or were moderate. The proportion of people who liked the fragrance on Street 2 was the largest. Moreover, the proportion of people who disliked the fragrance on Street 2 was the smallest, and on Streets 1 and 4 the highest. This might because the fragrance concentrations of Streets 1 and 4 were larger than the others; this concentration level might have been too high for some people, which might lead to higher discomfort. As can be seen, the trends on the four streets are almost the same.

Most participants thought that the subjective intensity of the fragrance was moderate. The proportions of people on Streets 1 and 4 who thought the subjective intensity was 'strong' were the highest, as were the proportions of people choosing 'very strong' on Streets 1 and 4, while that on Street 2 was the smallest. Thus, when the lilac was in full bloom, most people believed that the subjective intensity of the fragrance was acceptable. The fragrance on the street where the lilac was planted in double rows was stronger than on the streets with single rows of plants, and the fragrance of Syringa amurensis was more intense than that of Syringa oblata at the same planting density.

To eliminate the influence of visual factors, a partial correlation analysis was performed on the indicators of people's olfactory experiences, overall comfort, and traffic noise annoyance, as shown in Table 4. There was no significant correlation between overall comfort and the three indicators of people's olfactory experience. Also, traffic noise annoyance showed the same result. This possibly owes to lilac's common use as an urban greening plant in the city, resulting in high levels of familiarity and preference. People would then evaluate lilac highly, with little difference between the values and hence no correlation. While the perception of subjective intensity was also similar for different people in the same street, it also did not have correlated results. 


\section{Discussions and Conclusions}

This study investigated the effect of fragrance on the perception of traffic noise. An on-site experiment was carried out where participants evaluated overall comfort; traffic noise annoyance; satisfaction of audition, olfaction, and vision; congruency between fragrance and environment; and subjective opinion of a particular fragrance. The three main findings are described below.

First, the results of this study showed that the perception of the street traffic noise was affected by fragrance. This was reflected in an increase in the overall comfort of residents and daily pedestrians on the four streets, by 0.40 ; reduction of the traffic noise annoyance level by 0.34 ; an increase in the auditory satisfaction by 0.55 ; and the increase of olfactory satisfaction level by 0.89 (on a 5 -point scale). The subjective evaluation of the street with higher odour concentration was better than that of the streets with lower concentration, and the effect of fragrance on decreasing the traffic noise annoyance was more effective in the streets with lower than in those with higher sound levels.

It was also found that the congruency of the fragrance and the environment affected the perception of traffic noise. The evaluation of congruency between the fragrance and the environment showed a polarised trend, but most participants considered the fragrance congruent with the streets. The congruency of the street with the double rows of lilac was higher than that of the streets with single rows. The proportion of participants who thought the fragrance and environment were congruent was also the largest. Congruency had a significant moderately positive correlation with overall comfort and had a significantly low negative correlation with traffic noise annoyance. Thus, congruency of the fragrance and the environment increased, and traffic noise annoyance decreased.

In terms of people's olfactory experience, results showed that people had high familiarity with and preference for lilac's fragrance. The subjective intensity of the odour on the street with Syringa oblata planted in double rows and the street with Syringa amurensis planted in single rows was higher than that of the streets with single rows of Syringa oblata planted at the same density. However, there was no correlation between indicators of people's olfactory experience and the levels of overall comfort and 
traffic noise annoyance.

As can be seen from these main findings, the introduction of appropriate odour into open public space can improve people's evaluation of traffic noise; this is consistent with the results of previous study on sound-odour interaction in laboratory ( $\mathrm{Ba} \& \mathrm{Kang}$, 2019). Control of odour concentration should be paid attention, because even an odour with high preference level can lead to a decrease in olfactory satisfaction when the concentration is high. This is also consistent with previous studies, for some smells, even though they are liked by people in daily life, sometimes can still make people feel uncomfortable and annoyed when the concentration is inappropriate [55-57]. However, it is worth noting that even if olfactory satisfaction is not very high, higher odour concentration can still reduce attention to traffic noise.

In future urban planning and design, measures related to these results may be of use. Because of the positive correlation between traffic noise annoyance and congruency, in an environment with strong traffic noise, an odour with higher congruency can be introduced into the area in order to reduce the negative impact of traffic noise. High familiarity with and preference for a particular odour need not be taken into account, owing to the lack of estimable correlation with overall comfort and traffic noise annoyance.

This research could be expanded in a number of directions. While this study only covered the fragrance of lilacs, many other aromatic plants, such as rose, lavender, and common thyme, might have a similar impact; future studies can concentrate on other aromatic plants. Moreover, while two kinds of concentrations were studied in this experiment — corresponding to lilac planted in single rows and in double rows, respectively — future studies can allow for more accurate concentration gradients and can benefit from more advanced control over variables. Furthermore, the familiarity and preference for the odour in this study were high; future studies can target odour with low familiarity and/or preference. 


\section{Acknowledgement}

The work was supported by the National Natural Science Foundation of China (Grants No. 51438005 and 51778169), and the European Research Council (ERC) Advanced Grant (No. 740696).

\section{References}

[1] National Bureau of statistics of the People's Republic of China, Ministry of environmental protection of the People's Republic of China, China Statistical Yearbook on environment.2014, China Statistics Press, 2014.

[2] Y.T.P. Hai, T. Yano, T. Sato, T. Nishimura, Characteristics of road traffic noise in hanoi and ho chi minh city, vietnam, Appl. Acoust. 71 (5) (2010) 479-485.

[3] P.J. Lee, J. Kang, Effect of height-to-width ratio on the sound propagation in urban streets, Acta Acustica united Acustica 101 (1) (2015) 349-367.

[4] B. Wang, J. Kang, Effects of urban morphology on the traffic noise distribution through noise mapping: a comparative study between UK and China, Appl. Acoust. 72 (8) (2011) 556-568.

[5] H. Ma, X.R. Ji, T. Yano, Analysis of community response to noise in Chinese city, ACTA ACUSTUCA 33 (3) (2008) $275-282$.

[6] F.J. Mato-Méndez, M.A. Sobreira-Seoane, Blind separation to improve classification of traffic noise, Appl. Acoust. 72 (8) (2011) 590-598.

[7] K.P. Waye, A. Clow, S. Edwards, F. Hucklebridge, R. Rylander, Effects of nighttime low frequency noise on the cortisol response to awakening and subjective sleep quality, Life Sci. 72 (8) (2003) 863-875.

[8] S. Hygge, G.W. Evans, M. Bullinger, A prospective study of some effects of aircraft noise on cognitive performance in schoolchildren, Psychol. Sci. 13 (5) (2002) 469-474.

[9] D.J. Oldham, M.H. De Salis, S. Sharples, Reducing the ingress of urban noise through natural ventilation openings, Indoor Air 14 (s8) (2010) 118-126.

[10] J. Defrance, P. Jean, Integration of the efficiency of noise barrier caps in a $3 \mathrm{~d}$ ray tracing method. case of a t-shaped diffracting device, Appl. Acoust. 64 (8) (2003) 765-780.

[11] S. Aboqudais, A. Alhiary, Effect of distance from road intersection on developed traffic noise levels, Can. J. Civ. Eng. 31 (4) (2004) 533-538.

[12] H.A. Qdais, S. Aboqudais, Environmental impact assessment of road construction projects, Int. J. Water Resour. Dev. 65 (2) (2000) 203-219. 
[13] D. Ouis, Annoyance from road traffic noise: a review, J. Environ. Psychol. 21 (1) (2001) 101-120.

[14] H.M. Miedema, C.G. Oudshoorn, Annoyance from transportation noise: relationships with exposure metrics DNL and DENL and their confidence intervals, Environ. Health Perspect. 109 (4) (2001) 409-416.

[15] J. Kang, From dBA to soundscape indices: managing our sound environment, Front. Eng. Manage. 4 (2) (2017) 184-192.

[16] X. Zhang, M. Ba, J. Kang, Q. Meng, Effect of soundscape dimensions on acoustic comfort in urban open public spaces, Applied Acoustics. 133 (2018) 73-81.

[17] W. Yang, J. Kang, Acoustic comfort and psychological adaptation as a guide for soundscape design in urban open public spaces, In: Proceedings of the 17th International Congress on Acoustics (ICA), 2001.

[18] F. Soares, E. Freitas, C. Cunha, C. Silva, J. Lamas, S. Mouta, J.A. Santos, Traffic noise: annoyance assessment of real and virtual sounds based on close proximity measurements, Transport. Res. Transport Environ. 52 (2017) 399-407.

[19] C. Camusso, C. Pronello, A study of relationships between traffic noise and annoyance for different urban site typologies, Transport. Res. Transport Environ. 44 (2016) 122-133.

[20] L. Galbrun, T.T. Ali, Perceptual Assessment of Water Sounds for Road Traffic Noise Masking, Acoustics, 2012.

[21] A. Barbara and A. Perliss, Invisible Architecture: Experiencing Places through the Sense of Smell, 2006, Skira.

[22] A.H. Bokowa, Review of odour legislation, In: Bi International Conference on Environmental Odour Monitoring, 2010, pp. 31-36.

[23] R.A. Baron, The sweet smell of. helping: effects of pleasant ambient fragrance on prosocial behavior in shopping malls, Pers. Soc. Psychol. Bull. 23 (5) (1997) 498-503.

[24] K. Fox, The Smell Report, Social Issues Research Centre, 2006, available at: http://www.sirc.org/publik/smell.pdf, Accessed 24 April 2010.

[25] S.C. Knasko, Pleasant odors and congruency: effects on approach behavior, Chem. Senses 20 (5) (1995) 479-487.

[26] J. Reinarz, Past Scents: Historical Perspectives on Smell, University of Illinois Press, 2014.

[27] J. Xiao, M. Tait, J. Kang, A perceptual model of smellscape pleasantness, Cities 76 (2018) 105-115.

[28] J.M. Malnar, Sensory Design, U of Minnesota Press, 2004.

[29] V. Henshaw, Urban Smellscapes : Understanding and Designing City Smell Environments, Routledge, 2014.

[30] A. D'Errico, My smelling avatar - Scents in new media and technology. For the Deeper Sense. Scent as Media in Art, Design and Communications - For the deeper senseFür den tieferen Sinn - Duft als Medium in Kunst, Design und Kommunikation, 2016.

[31] M. Moss, L. Oliver, Plasma 1,8-cineole correlates with cognitive performance following exposure to rosemary essential oil aroma, Ther. Adv. Psychopharmacol. 2 (3) (2012) 103-113. 
[32] C. Spence, The Handbook of Multisensory Processes. The Handbook of Multisensory Processes, MIT Press, 2004.

[33] M.L. Ye, Five Senses Applied in Landscape Design, Doctoral dissertation Tianjin University, 2009.

[34] M. Southworth, The sonic environment of cities, Environ. Behav. 1 (1) (1967) 49-70.

[35] P. Lercher, B. Schulte-Fortkamp, The relevance of soundscape research to the assessment of noise annoyance at the community level, In: Proceedings of the Eighth International Congress on Noise as a Public Health Problem, 2003, pp. 225-231.

[36] T. Hashimoto, S. Hatano, Effects of factors other than sound to the perception of sound quality, In: 17th ICA Rome, CD-ROM, 2001.

[37] L.M. Anderson, Effects of sounds on preferences or outdoor settings, J. Environ. Behav. 15 (1983) 539-566.

[38] F. D'Alessandro, L. Evangelisti, C. Guattari, G. Grazieschi, F. Orsini, Influence of visual aspects and other features on the soundscape assessment of a university external area, Build. Acoust. 25 (3) (2018) 199-217.

[39] C.M. Van Reekum, H. vann de Berg, N.H. Frijda, Cross-modal preference acquisition: evaluative conditioning of pictures by affective olfactory and auditory cues, Cognit. Emot. 13 (6) (1999) 831-836.

[40] H.Q. Dinh, N. Walker, C. Song, A. Kobayashi, L.F. Hodges, Evaluating the importance of multi-sensory input on memory and the sense of presence in virtual environments, In: Virtual Reality, 1999. Proceedings. IEEE, vol. 445, IEEE, 2002, p. 222.

[41] R. Michon, J.C. Chebat, The Interaction Effect of Music and Odour on Shopper Spending, Unpublished doctorial dissertation School of Retail Management, Ryerson University, Toronto, Canada, 2006.

[42] M. Ba, J. Kang, A laboratory study of the sound-odour interaction in urban environments, Build. Environ. 147 (2019) 314-326.

[43] T. Engen, Odor Sensation and Memory, Praeger, 1991.

[44] T.T. Zhang, Y.H. Yang, S.Q. Wang, Z.L. Kang, Extraction technologies for essential oil of Syringa oblata Lindl and aroma constituents analysis of Syringa oblata Lindl at different flowering periods, Hunan Agric. Sci. 2011 (1A) (2011) 97-100.

[45] K. Ma, The Evolution of City Streets and the Exploration of New Model, Doctoral dissertation Tianjin University, 2009.

[46] H. Distel, S. Ayabe-Kanamura, M. Martínez-Gómez, I. Schicker, T. Kobayakawa, S. Saito, et al., Perception of everyday odorscorrelation between intensity, familiarity and strength of hedonic judgement, Chem. Senses 24 (2) (1999) 191-199.

[47] J. Kang, Urban Sound Environment, CRC Press, 2006.

[48] W. Yang, J. Kang, Acoustic comfort evaluation in urban open public spaces, Appl. Acoust. 66 (2) (2005) 211-229.

[49] J. Liu, J. Kang, H. Behm, T. Luo, Effects of Landscape on soundscape perception: Soundwalks in city parks, Landscape and Urban Planning. 123 (2014) 30-40. 
[50] P. Rodaway, Sensuous Geographies : Body, Sense and Place, Routledge, 2011.

[51] P. Zahorik, Assessing auditory distance perception using virtual acoustics, J. Acoust. Soc. Am. 111 (4) (2002) 1832-1846.

[52] G. Rodriguez, J. Pallant, J. Mincer, L. Lee, D.R. Helsel, B. Laplante, et al., Spss Survival Manual, Nsw Australia Allen \& Unwin, 2005.

[53] Chinese flora Committee of Chinese Academy of Sciences, M.Z. Zhang, B.M. Liao, R.L. Lu, Flora of China, Logania, 1992.

[54] F. Li, M. Cai, J.K. Liu, Analysis of the effects of a bus stop on traffic noise, Environ. Monitor. China 25 (1) (2009) $105-108$.

[55] P.M. Cavalini, L.G. Koeter-Kemmerling, M.P.J. Pulles, Coping with odour annoyance and odour concentrations: three field studies, J. Environ. Psychol. 11 (2) (1991) 123-142.

[56] S. Cohen, G.W. Evans, D. Stokols, D.S. Krantz, Behavior, Health, and Environmental Stress, Springer Science \& Business Media, 2013.

[57] H.M.E. Miedema, J.M. Ham, Odour annoyance in residential areas, Atmos. Environ. 22 (11) (1988) 2501-2507. 